\title{
Establishment of the Standard Prophylactic Strategy for Peritoneal Recurrence and Proposal of the Optimal Therapeutic Protocol for Gastric Cancer
}

\author{
Shimada S1, Kuramoto M11, Ikeshima S1, Matsuo A1, Ikuta Y1, \\ Kuhara $\mathrm{H}^{1}$ and Baba $\mathrm{H}^{2}$ \\ ${ }^{1}$ Department of Surgery, Yatsushiro Social Insurance General Hospital \\ ${ }^{2}$ Department of Gastroenterological Surgery, Graduate School of \\ Medical Sciences, Kumamoto University, Kumamoto
}

Japan

\section{Introduction}

Advances in diagnosis and surgical techniques have improved the conditions of patients with gastric cancer. Peritoneal dissemination, however, is still the most frequent cause of death, and the prognosis of patients with peritoneal metastasis of gastric cancer is extremely poor (Balfour, 1973; Hioki et al.,2010; Maruyama, 1987; Makino et al., 2010; M. Yamamoto et al., 2009). In patients with serosal invasion, about half develop peritoneal recurrence and die from the disease within the first 2 years of follow-up, even if curative resection is performed (Abe et al., 1995; Ikeguchi et al., 1994; Kaibara et al., 1987; Moriguchi et al., 1992; Ribero et al., 1998). Furthermore, it has been reported that the survival span of the patients with cytology-positive peritoneal lavage fluid and without the macroscopic peritoneal dissemination $(\mathrm{CY}+/ \mathrm{P}-)$ of gastric cancer was almost the same as that of patients with $\mathrm{P}+$ (Boku, et al., 1990; Shimada et al., 2003), and the 5-year survival rate of patients with $\mathrm{CY}+/ \mathrm{P}$ - is only $2 \%$ (Bando et al., 1999). Accordingly, the treatment recommendations for gastric cancer in the event of positive cytology range from palliative chemotherapy to attempts at neo-adjuvant therapies followed by surgical resection. However, the results of published randomized clinical trials of adjuvant perioperative intra-peritoneal chemotherapy have not fully demonstrated any significant improvement in survival as compared with surgery alone, especially in the cases with P+ (Cunliffe \& Sugarbaker, 1989; Cheong et al., 2007; Hagiwara et al., 1992; Ikeguchi et al., 2005; Kunisaki et al., 2002; Sauter et al., 1994). Therefore, a reliable and appropriate standard prophylactic regimen for peritoneal recurrence in patients with gastric cancer needs be established.

Clinical and pathologic factors that have been found to correlate with the presence of positive cytology are usually at an advanced stage of the disease (Burke et al., 1998; Iitsuka et al., 1979; Koga et al., 1984; Ribeiro et al.,2006; Yawata et al.,1998). The most likely cause is the presence of intra-peritoneal free cancer cells from the serosal surface of the primary cancer and their implantation on the peritoneum. Furthermore, our previous study proved 
that lymph node dissection opened the lymphatic channel and spread viable cancer cells into the peritoneal cavity (Marutsuka et al., 2003). This could explain the main reason for the peritoneal recurrence after curative surgery for patients with non serosa-invasive gastric cancer.

Peritoneal dissemination is probably completed by the implantation of peritoneal free cancer cells exfoliated from serosa-invasive tumors. Consequently, it is very important to prevent peritoneal metastasis prior to the fixation and progression of free cancer cells to the peritoneum in patients with advanced gastric cancer. This is because the presence of intraperitoneal free cancer cells without macroscopic dissemination could possibly indicate a condition wherein the implantation of cancer cells on the intra-peritoneal wall has not yet occurred.

Based on this assumption, we have been advocating the adoption of 'extensive intraoperative peritoneal lavage' (EIPL) (Shimada et al., 2002; K. Yamamoto et al., 2005) as a reliable and practical intra-operative technique as an adjuvant therapy for preventing the implantation of cancer cells on the intra-peritoneal wall after a potentially curative resection combined with intra-peritoneal chemotherapy (EIPL-IPC). EIPL is very simple and can be performed anywhere and at anytime. It is a rather efficient method for reducing the number of intra-peritoneal free cancer cells to zero potentially, when the cancer cells are analyzed by a detection system using real-time reverse transcriptase-polymerase chain reaction (RTPCR), and intra-peritoneal chemotherapy subsequent to EIPL could be effective for eradicating the remaining cancer cells. We have confirmed the clinical effectiveness of EIPL by ultra-rapid quantitative RT-PCR protocol (Marutsuka et al., 2003). Very few intraperitoneal free cancer cells could be detected in the washing fluid after 6 to 8 washes. Finally, our recent prospective randomized controlled clinical trial clearly revealed that EIPL therapy significantly improved the 5-year survival rate of advanced gastric patients with intra-peritoneal free cancer cells (Kuramoto et al., 2009).

In this manuscript, the risk factors on peritoneal recurrence from clinicopathological features of gastric carcinoma and the contribution of EIPL method to the remarkable improvement in the 5-year survival for patients with $\mathrm{CY}+/ \mathrm{P}$ - on clinical trials is reviewed, and the optimal treatment protocol for patients with gastric cancer is proposed.

\section{Clinicopathological features and risk factors on peritoneal recurrence for gastric carcinoma}

Results of specific preoperative studies, intraoperative findings, postoperative pathologic staging, clinical management, and follow-up data from 2117 patients underwent gastric resection with D2 lymph nodes dissection for primary gastric carcinoma were registered prospectively (Shimada S, et al.). Preoperative diagnosis was made on the basis of endoscopic, radiologic, and endoscopic ultrasonographic (EUS) (Kida et al., 1998) findings. Pathologic diagnosis and classifications were based on the Japanese Classification of Gastric Carcinoma by the Japanese Research Society for Gastric Cancer (Japanese Research Society for Gastric Cancer, 1999).

The incidences of lymph node metastasis from tumors with mucosal (M), submucosal (SM), and advanced gastric cancer were $2.5 \%, 20.2 \%$, and $71.2 \%$, respectively. The detailed pathological analysis revealed that all $M$ tumors with lymph node metastasis $(n=14)$ had ulceration or ulceration scar (UL+) in the lesions even if the lesion was smaller than $1.5 \mathrm{~cm}$ in diameter. On the other hand, no $\mathrm{M}$ tumor without ulceration or ulceration scar (UL-) 
$(n=328)$ had any lymph node metastasis. In advanced gastric cancer, approximately $57 \%$ of the metastatic tumors had distant lymph nodes metastasis. Serosal invasion was also popular in advanced gastric cancer; approximately $50 \%$ of the advanced tumors had serosal invasion.

Fig 1 showed cancer-specific 5-year survival rates of gastric cancer according to the tumor depth. Gastric resection with D2 lymph nodes dissection for primary gastric carcinoma yielded good prognosis in M and SM tumors; $98 \%$ and $95 \%$ of the cancer-specific 5-year survival rates, respectively. There were no apparent prognostic factors in patients with $\mathrm{M}$ tumors. In patients with SM tumors, the cancer-specific 5-year survival of those with lymph node metastasis was significantly lower than that of those without such metastasis $(77.6 \% \mathrm{vs}$ 98.2\%; $P<0.001)$. An sharp decrease in survival was seen between patients with two positive nodes and those with three positive nodes, and the cancer-specific 5-year survival rate of patients with three or more metastatic lymph nodes was significantly lower than that of those with one or two nodes $(P=0.041)$. Multivariate analyses revealed that the involvement of three or more lymph nodes was the sole independent prognostic determinant $(P=0.016)$; the level of nodal metastasis was not an independent prognostic factor $(P=0.384)$. In advanced gastric cancer, serosal invasion was the strong prognostic factor as well as the factor of more than three lymph nodes metastasis. These results suggest that gastric cancer patients with lymph nodes metastasis and serosal invasion should be given special weight of additional therapy after surgery (Fig. 1).

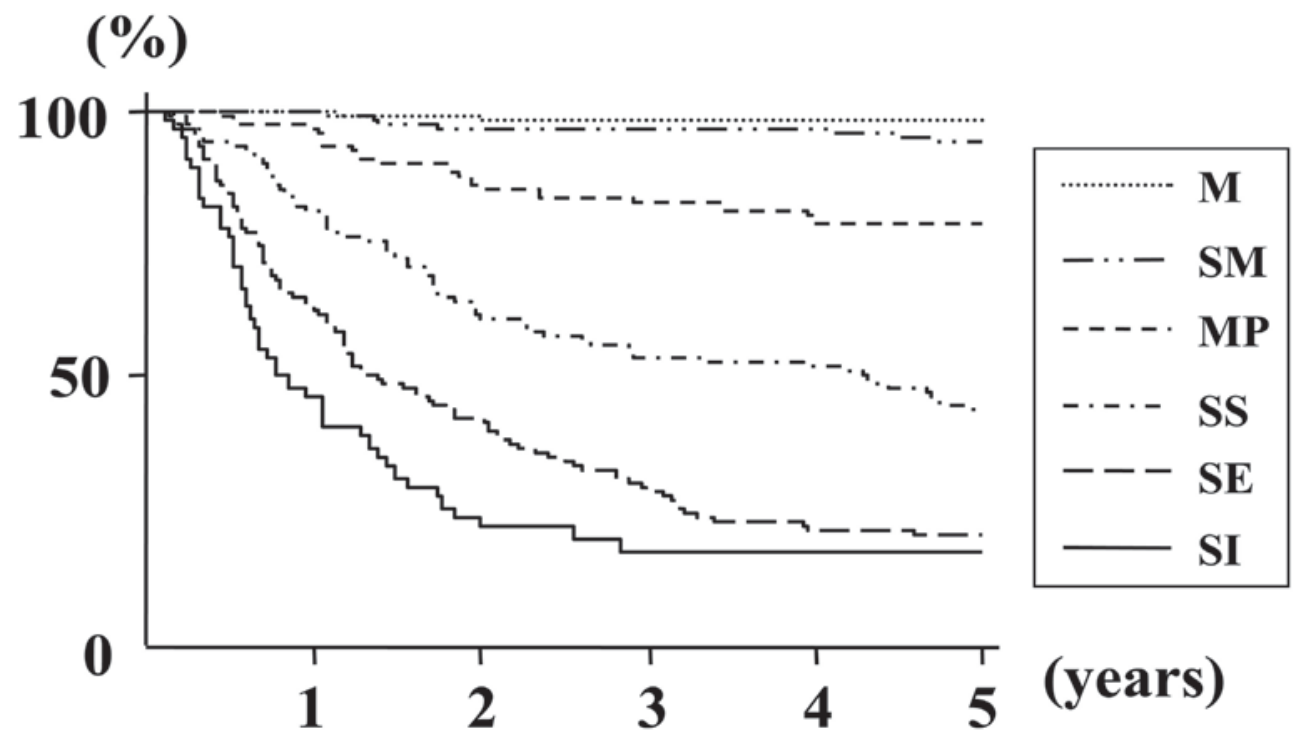

Fig. 1. Cancer-specific 5-year survival rates of gastric cancer according to the tumor depth. M: mucosal tumor, SM: submucosal tumor, MP: tumor with muscularis proprial invasion, SS: tumor with subserosal invasion, SE: tumor with serosal invasion, SI: tumor invasion of adjacent structures (Shimada et al., 2003) 


\section{Real-time detection system for Intra-peritoneal free cancer cells}

An ultra-rapid quantitative RT-PCR protocol, which is a combined system of an ultra-rapid RT-PCR, using a fully automated mRNA extractor and a real-time one-step RT-PCR system with a hybridization probe format, has been established to diagnose intra-peritoneal cancer cells spread during a surgical operation (Marutsuka et al., 2003). This new method enabled us to obtain the results of RT-PCR within approximately 70 minutes after sampling. Furthermore, we carried out multiple-marker RT-PCR assays in a combination of carcinoembryonic antigen (CEA) and cytokeratin 20 (CK20) to eliminate false positive results and to improve specificity. This assay system was able to detect at least 10 cancer cells in $1 \times 10^{7}$ of leukocytes, indicating comparable sensitivity to conventional nested-RTPCR. Accordingly, the accurate diagnosis of the spread of intra-peritoneal cancer cells was done during the actual operation (Fig. 2).
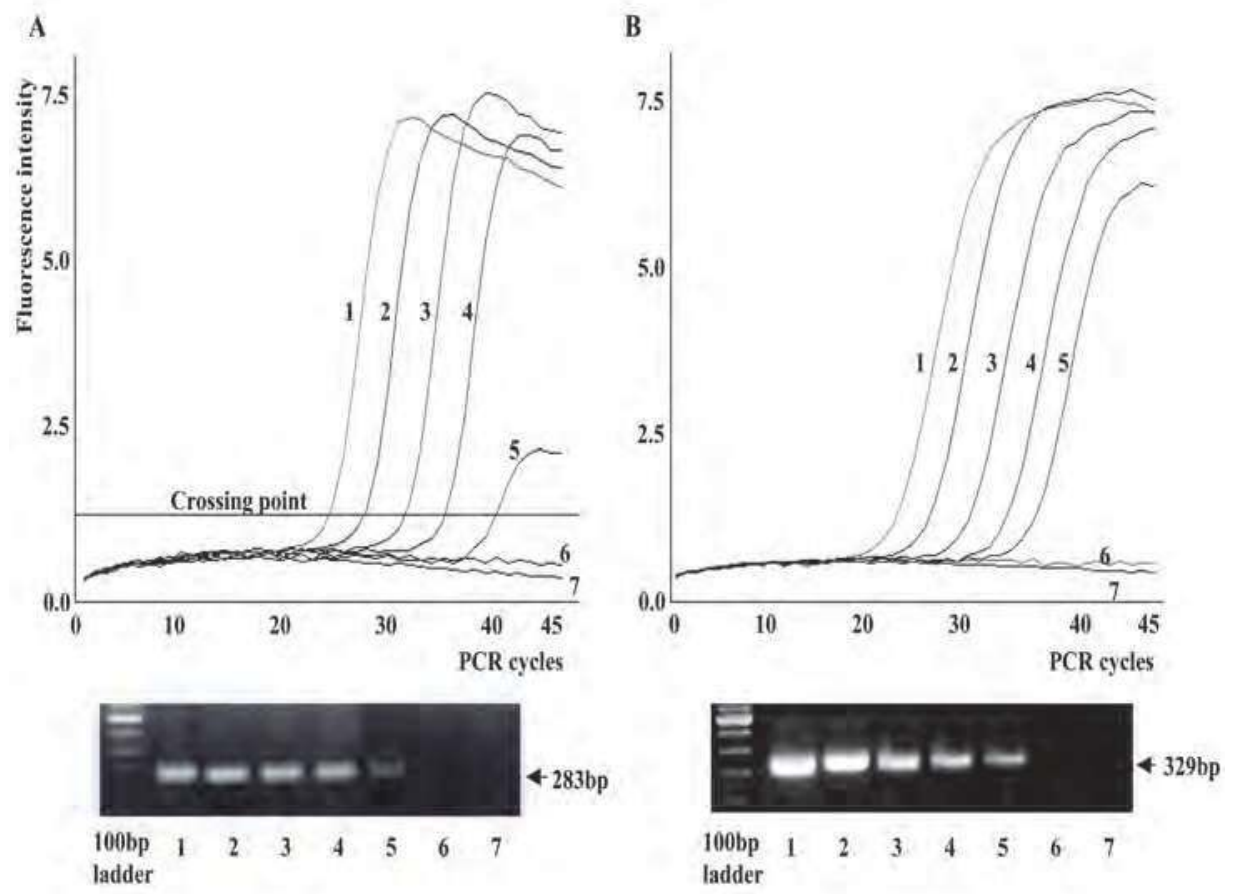

Fig. 2. Sensitivity of ultra-rapid quantitative RT-PCR assay by LightCyclerTM using CEA (A) and CK20 (B) mRNA marker. Curves and lanes 1-5 were serially diluted $10^{5}$ cells to $10^{1}$ cells of WiDr colon carcinoma cell in $10^{7}$ leukocytes from healthy volunteer, respectively; curve and lane 6: $10^{7}$ leukocytes from healthy volunteer; curve and lane 7: no template. This assay system could detect at least $10 \mathrm{WiDr}$ colon carcinoma cells in $10^{7}$ leukocytes. The PCR products were analyzed by $2 \%$ agarose gel electrophresis, and they were matched to the expected sizes of CEA and CK20. 'Crossing points' were used to establish an external standard curve for quantification. Forty-five rounds of amplification were completed within 30min. (Marutsuka et al., 2003) 


\section{Mechanisms of peritoneal recurrence after operation for non-serosa- invasive gastric cancer}

Even though curative surgery has been performed for patients with non- serosa-invasive gastric cancer, some patients die of peritoneal recurrence (Abe et al., 1995; Bozzetti et al., 1986; Fink \& Longmire, 1991; Shimada et al., 2001a; Yoo et al., 2000). As shown in Table 1, even in patients with early gastric cancer, three out of 420 died of peritoneal recurrence.

\section{Mucosal tumor Submucosal tumor}

No. of patients

Lymph node metastasis

(\%)

Cancer death

(5-year survival rate: \%)
621

14

6

(99.0)
430

\section{4}

(19.5)

26

(94.0)

\section{Recurrence}

Hematogenous

Lymphatic

Peritoneal

Table 1. Lymph node metastasis and cancer death in early gastric carcinoma treated by D2 gastrectomy

Our investigations based on the intraoperative ultra-rapid RT-PCR system elucidated the cause (Marutsuka et al., 2003). Peritoneal lavage samples from 63 patients with non-serosainvasive gastric carcinoma were obtained at laparotomy and immediately after lymph node dissection. To identify the free cancer cells in the samples, CEA and CK20 specific RT-PCR were performed using LightCycler ${ }^{\mathrm{TM}}$ method in combination with an automated mRNA extractor. In the peritoneal lavage samples from non-serosa-invasive cases after lymph node dissection, a CEA mRNA product was detected in 15 of 63 patients (23.8\%) (Fig. 3). This was not evident in the mucosal (M) tumors, but was identified in three (14.3\%), five (33.3\%), and seven (53.8\%) patients with submucosal (SM), muscularis propria (MP), and subserosal (SS) tumor, respectively. As regards CK20 mRNA, the product was identified in 14 of 63 patients (22.2\%). Just like CEA mRNA, CK20 mRNA was not detected in the mucosal tumors, but was identified in three (14.3\%), five (33.3\%), and six patients $(46.2 \%)$ with SM, $\mathrm{MP}$, and SS tumor, respectively. Both CEA mRNA and CK20 mRNA were detected in three $(14.3 \%)$, four $(26.7 \%)$, and six $(46.2 \%)$ with SM, MP, and SS tumor, respectively. In consequence, the number of free cancer cells, calculated by the standard curve for cancerous cells, were $3.5 \pm 3.7$ (mean $\pm \mathrm{SD}$ ), $12.1 \pm 9.6$, and $124.8 \pm 224.0$ cells $/ 100 \mathrm{ml}$ in the lavage after lymph node dissection from SM, MP, and SS tumor, respectively. 
This study using the intraoperative ultra-rapid RT-PCR system revealed that free cancer cells were found in $14.3 \%$ and $26.7 \%$ of the lavage fluid after lymph node dissection from patients with SM and MP tumors, respectively. Statistical analysis demonstrated that lymph node metastasis was the independent predictor for the existence of intra-peritoneal free cancer cells after lymph node dissection.

From our previous study on 1272 cases of gastric carcinoma, $1 / 257$ cases $(0.4 \%)$ of SM and $6 / 136$ cases $(4.4 \%)$ of MP cases developed peritoneal metastasis after potentially curative operation (Shimada et al., 2001a, 2003). Among them, $86 \%$ of the patients had lymph node metastasis and/or lymphatic invasion. Our results determined that lymph node dissection is the main factor for spreading viable free cancer cells into the peritoneal cavity. Thus, it was proved that lymph node dissection opens the lymphatic channel and spreads viable cancer cells into the peritoneal cavity.

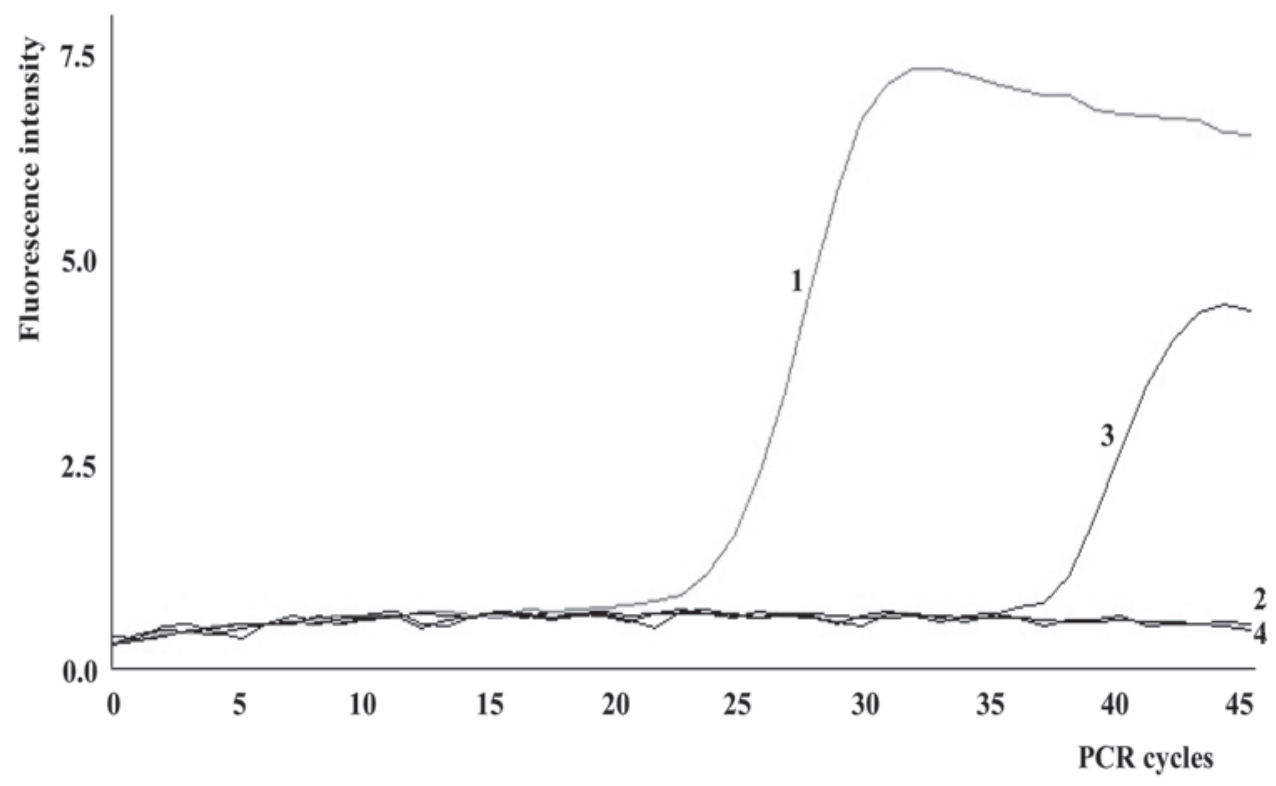

Fig. 3. Representative results of ultra-rapid RT-PCR by LightCyclerTM in a patient with SM tumor of well-differentiated adenocarcinoma with lymph node metastasis and lymphatic invasion. Curve 1: WiDr colon cancer cells as positive control; curve 2: intraperitoneal lavage sample at laparotomy; curve 3: intraperitoneal lavage sample immediately after lymph nodes dissection; curve 4: no template as negative control. (Marutsuka et al., 2003)

\section{EIPL therapy}

To date, there are no definitive effective therapies for peritoneal carcinomatosis. Therefore, attention has been paid to detecting peritoneal free cancer cells in patients with advanced gastric carcinoma without overt peritoneal metastasis, and attempts to prevent peritoneal metastasis (S. Fujimoto et al.,1999; T. Fujimoto et al., 2002; Hamazoe et al., 1994; Hayes et al., 1999; Rosen et al, 1998; C.C. Wu et al., 1997, Yonemura et al., 1995; Yu et al., 1998). 
The status of $\mathrm{CY}+/ \mathrm{P}$ - includes the condition where peritoneal implantation has not occurred yet. We have proposed that EIPL is a quite formidable method for reducing the number of cells to potentially zero, just like the so-called 'limiting dilution' approach. EIPL was performed in five cases of serosa-invasive (SE) gastric carcinoma with $\mathrm{CY}^{+} / \mathrm{P}_{-}$, and its efficacy was evaluated by the ultra-rapid quantitative RT-PCR protocol (Shimada et al., 2002). Sequential washing of intra-peritoneal free cancer cells of $3.8 \times 10^{5} \pm 1.4 \times 10^{5} / 100 \mathrm{ml}$ of lavage decreased the number to $2.8 \pm 1.5$ cells by 6 to 8 washes. Free cancer cells were not detected in the washing fluid after that (Fig. 4).

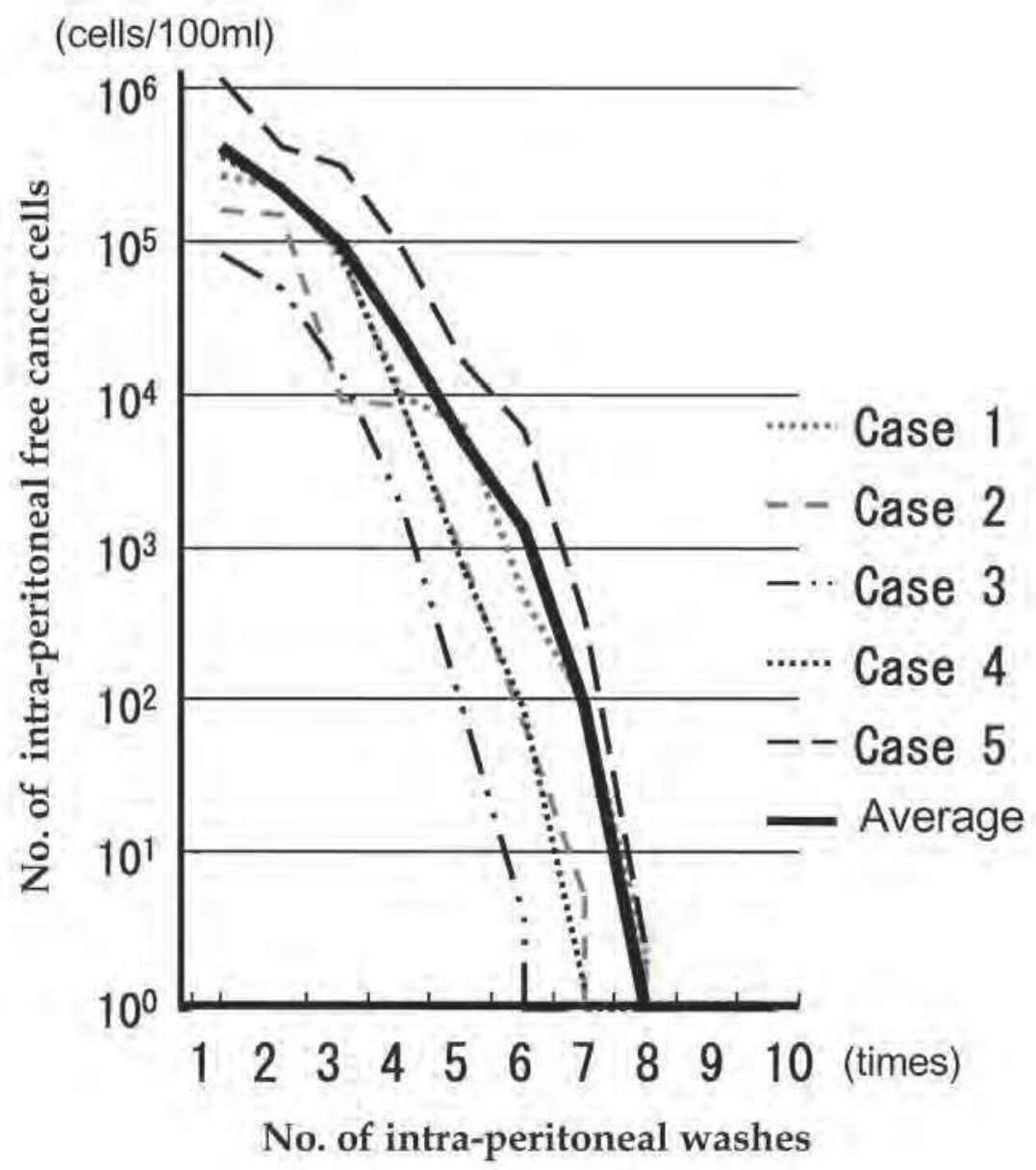

Fig. 4. Changes in numbers of intra-peritoneal free cancer cells in five gastric cancer patients with CY+ treated by EIPL therapy. The numbers of free cancer cells in $100 \mathrm{ml}$ of samples from the first to the 10th wash using each 1 litter of saline were quantitated by ultra-rapid RT-PCR. The free cancer cells in the lavage fluids were serially diluted by 8 litters of saline and disappeared in washing fluids after the 8 th wash. 
On the other hand, $2.8 \times 10^{4} \pm 4.5 \times 10^{4}$ of intra-peritoneal free cancer cells still remained in $100 \mathrm{ml}$ of the lavage when not treated with EIPL. Our preliminary subset analysis based on 24 consecutive patients with $\mathrm{CY}+/ \mathrm{P}$ - who underwent curative surgical treatment for advanced gastric cancer, and were followed up for 2 years or until death, has shown a statistically significant $(P=0.017)$ improvement of a two-year survival rate when treated with EIPL as compared with when not treated with EIPL (Shimada et al., 2002).

\section{Five-year survival rates of patients who had EIPL therapy through a prospective randomized clinical trial}

Following a pioneering study (Shimada et al., 2002; K. Yamamoto et al., 2005), we performed the EIPL therapy for advanced gastric cancer patients with $\mathrm{CY}+/ \mathrm{P}$ - in order to clearly clarify the distinct 5-year survival effects through a prospective randomized multicenter trial (Kuramoto et al., 2009). A total of 88 gastric cancer cases with CY+/P- from 1522 patients with advanced gastric cancer at multicenter were enrolled in this study, and were randomly allocated to three groups: surgery alone group, surgery plus intra-peritoneal chemotherapy (IPC) group, and surgery plus EIPL and IPC (EIPL-IPC) group. In EIPL-IPC group, 100mg of cisplatin (CDDP) was administered into the peritoneal cavity, after the EIPL treatment. Peritoneal lavage for the surgery alone group and the IPC group was done with 3 liters (1 liter, three times) before the closure of the abdominal wall or intra-peritoneal chemotherapy, respectively.

The overall five-year survival rate of the patients with EIPL-IPC was $43.8 \%$, and this data was significantly higher than that of the IPC group $(4.6 \%, P<0.0001)$ and the surgery alone group $(0 \%, P<0.0001)$ (Fig. 5). Among various recurrent patterns, the EIPL-IPC group had a significantly lower incidence of peritoneal recurrence than either of the other groups $(P<$ 0.0001). Univariate and multivariate analyses clearly revealed that EIPL was the most significant impact factor.

The results of the present prospective randomized multicenter study far exceeded our expectations and showed a remarkably much better prognosis than previous studies on gastric cancer patients with $\mathrm{CY}+/ \mathrm{P}$-. For example, a study on the median survival time (MST) of 91 patients with $\mathrm{CY}+\mathrm{P}$ - who had potentially curative resection stated survival to be only 386 days (Kodera et al., 1999), and the 5-year overall survival rate has been 13\% (Rosenberg et al., 2006). In this study, the surgery alone group as well as the IPC group also showed similar results to the reports just cited. Surprisingly, however, in the $\mathrm{CY}+/ \mathrm{P}$ - group the overall five-year survival rate and MST were $42.1 \%$ and 35 months, respectively, and showed remarkably significant $(P<0.0001)$ improvement of both survival and MST. The results appeared so convincing and promising to us as to serve as a solid basis for employing the EIPL-IPC therapy with a great degree of confidence and high expectations.

\section{Proposal of the optimal and practical therapeutic strategy for gastric cancer}

Based on the data presented in this review, the authors propose the following treatment protocol for gastric cancer (Fig. 6). Accurate diagnosis of mucosal or submucosal cancer is made macroscopically including an EUS examination. Mucosal and submucosal invasion is correctly diagnosed in 75 to $85 \%$ of patients using EUS. All mucosal lesions with UL- should be treated by endoscopic submucosal dissection (ESD). If histologic examination of the ESD 
specimen reveals complete resection, the treatment is considered to be perfect and the patient only needs follow-up. If histologic examination reveals an incomplete resection, laparoscopic local resection is required. For a mucosal tumor with UL+, laparoscopic gastrectomy with D1 is indicated. All macroscopic SM and advanced cancer cancer (MP, SS, SE and SI) should be treated by gastrectomy with D2 (Shimada et al., 2001a).

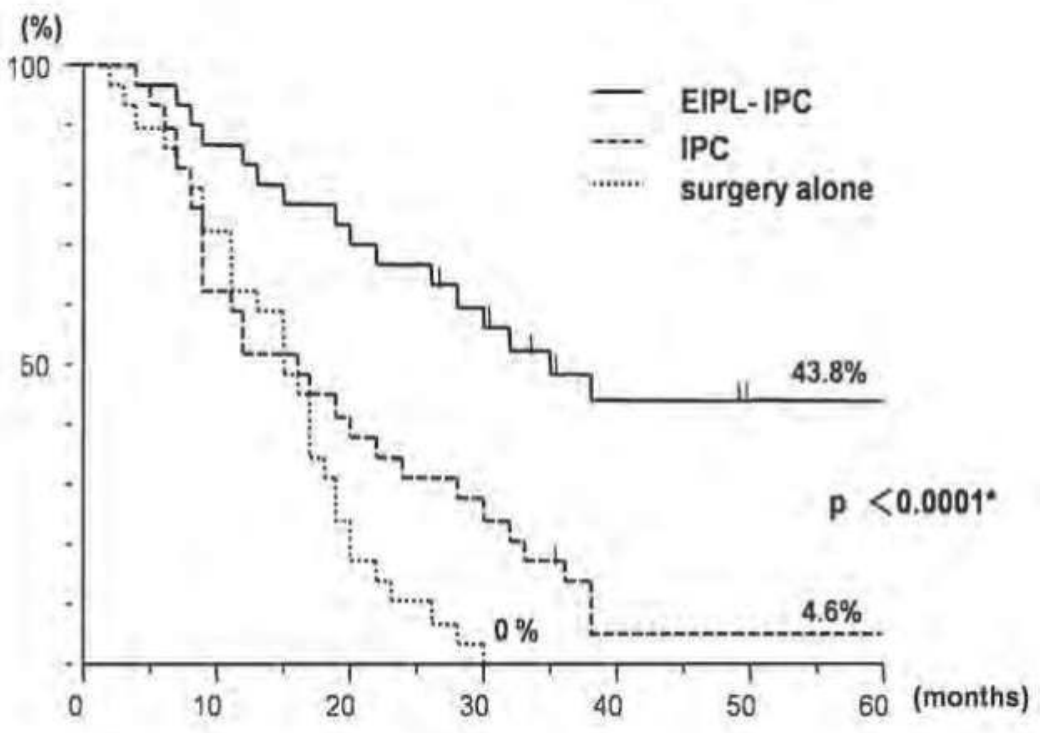

$\begin{array}{lrrrrrrr}\begin{array}{l}\text { Number at risk } \\ \text { EIPL-IPC }\end{array} & 30 & 27 & 22 & 16 & 11 & 9 & 8 \\ \text { IPC } & 29 & 22 & 12 & 8 & 1 & 1 & 1 \\ \text { surgery alone } & 29 & 23 & 7 & 1 & 0 & 0 & 0\end{array}$

Fig. 5. The survival curves for 88 patients stratified according to the treatment. *By log-rank test. (Kuramoto et al., 2009)

Although a Dutch report has described the high post-operative morbidity and hospital mortality after gastrectomy with D2 lymph node dissection (Bonenkamp et al., 1995), D2 resections appear to be feasible and safe in Japanese (Japanese Research Society for Gastric Cancer, 1999; Kuramoto et al., 2009; Maruyama, 1987; Nakamura et al., 1992; Ohgaki et al., 1999; Sano et al., 2004; Shimada et al., 2001b; C.W. Wu et al., 2008) and certain Western patients (Harrison et al., 1998; Lim et al., 2007). In our study, operative morbidity and hospital mortality was $1.5 \%$ (16 of 1051) and $0.5 \%$ (5 of 1051) respectively. Certain factors in the Dutch patients such as a more advanced tumor stage or larger physical build to the Japanese patients in this study might have influenced the high morbidity and mortality. The present study on patients with gastric cancer suggested that the potential benefits of D2 operation outweigh the risk of increased postoperative morbidity and mortality. Therefore, advanced gastric cancer should be treated by gastrectomy with $\mathrm{D} 2$, and D2+a may be 
necessary for patients with apparent N2 and/or N3 lymph nodes metastasis. Complete extirpation of gastric cancer with a sufficient resection margin from the tumor and the removal of metastatic lymph nodes is the only treatment that offers hope of cure for patients with gastric cancer (Balfour, 1973; Harrison et al., 1998; Japanese Research Society for Gastric Cancer, 1999; Maruyama, 1987; Shimada et al., 2003; Zhang et al., 2010). However, as a matter of course, excessive gastrectomy and lymph node dissection have to be avoided for the adverse effects they have on a patient's subsequent quality of life.

From the viewpoint of prophylactic strategy against peritoneal recurrence, the findings presented in this paper should greatly transform the surgical treatment for gastric cancer, including non-serosa-involved tumors. The authors strongly advocate for the adoption of the new treatment protocol for gastric cancer as shown in Fig. 6.

After the appropriate tumor resection and lymph node dissection, our novel EIPL regimen serves an extremely important role for gastric patients with high peritoneal recurrent risks such as serosal invasion and lymph node metastasis. The innovative EIPL method is very practical and the theoretical basis creates high expectation as to the effects of cyto-reduction, potentially to nil. Furthermore, the EIPL therapy is simple, very little time-consuming, inexpensive, it is not curtailed by place or time, and does not need any special techniques or devices in order to be applied. In addition, even if a few cancer cells were to remain after EIPL therapy, these cells might find it difficult to survive and/or to disseminate due to the effects of IPC or postoperative systemic chemotherapy with S1 (Ishizoe et al., 2006; Shirasaka et al., 2000; Sugimachi et al., 1999) .

Conventional cytological examination with Papanicolou staining (Papanicolaou, 1963) has been reported to lack sensitivity, and it is suggested that occult free cancer cells are present at the time of the operation in such cases. Therefore, improvements have been made by many investigators using immunological methods with selected monoclonal antibodies or real-time RT-PCR for the detection of free cancer cells in the peritoneal washes (Benevolo et al., 1998; Broll et al., 2001; Dicken et al., 2006; Kodera et al., 2002; Saito et al., 2007; P. Vogel et al., 1999; I. Vogel \& Kalthoff, 2001). These methods have allowed the identification of cytology false-negative cases in gastric cancer. However, because these means are not generally available at the actual time of the operation, a cytological examination is commonly performed to detect the existence of free cancer cells in the peritoneal cavity. From these cautionary points of view, it is only prudent that the EIPL-IPC therapy would be employed for all patients with serosa-involved gastric cancer and regardless of CY+/P-.

On the other hand, although curative surgery has been used for patients with non-serosainvolved gastric cancer, some die of peritoneal recurrence. One of the reasons postulated for peritoneal dissemination in non-serosa-involved gastric cancer is that the lymph node dissection might open lymphatic channels and spread viable cancer cells to the peritoneal cavity (Fink \& Longmire, 1991). We have demonstrated that free cancer cells were found in the lavage fluid after the lymph node dissection in $26.7 \%$ of patients with muscle-involved tumors, suggesting that the surgical operation itself causes the peritoneal dissemination of the these cancer cells (Marutsuka et al., 2003). Therefore, EIPL therapy is also strongly recommended for non-serosa-involved gastric carcinomas suspected of lymphatic invasion through surgery, or positive real-time RT-PCR for detection of free cancer cells in the peritoneal washes after D2 operation for non-serosa-involved tumor, including early gastric carcinoma (Fig. 6). 


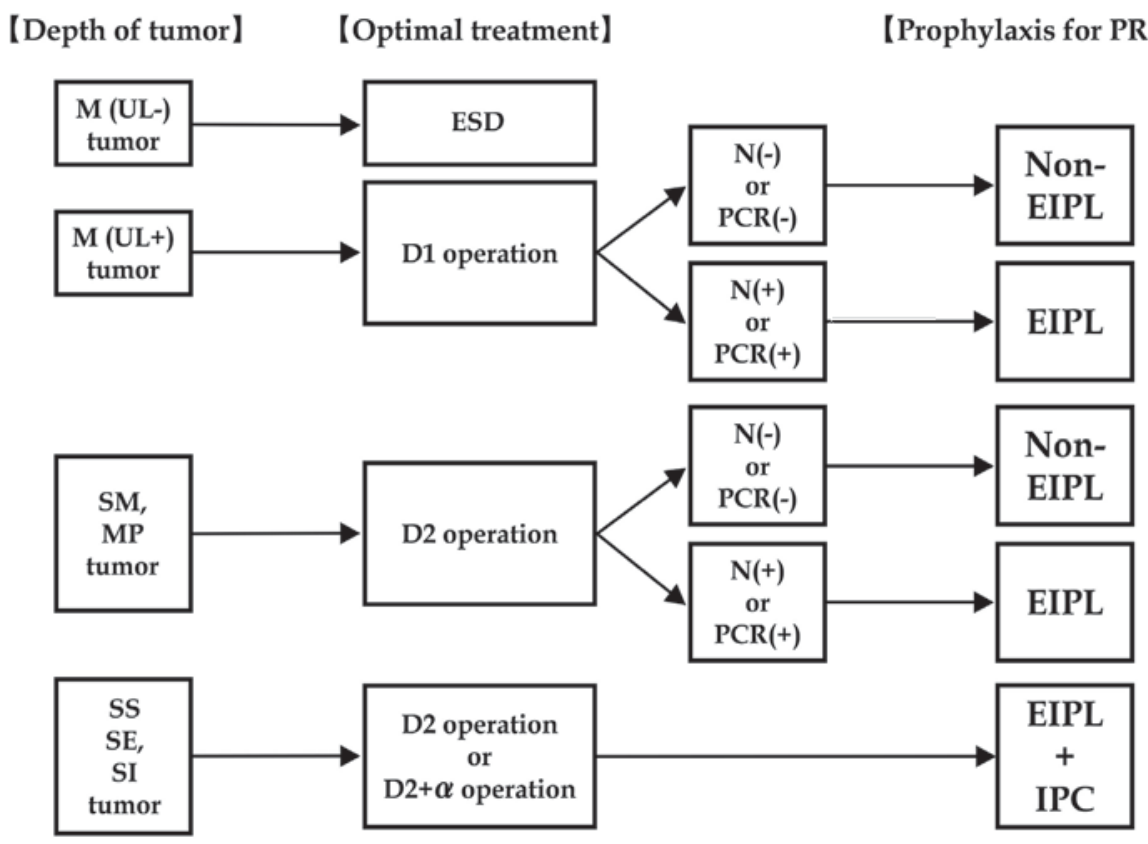

Fig. 6. A practical and optimal treatment protocol for gastric cancer. PR: peritoneal recurrence, M: mucosal tumor, SM: submucosal tumor, MP: tumor with muscularis proprial invasion, SS: tumor with subserosal invasion, SE: tumor with serosal invasion, SI: tumor invasion of adjacent structures, UL+: tumor with ulceration or ulceration scar, UL-: tumor without ulceration or ulceration scar, ESD: endoscopic submucosal dissection, D1 operation: gastrectomy with dissection of group 1 lymph node, D2 operation: gastrectomy with dissection of group 1 and 2 lymph node, $\mathrm{N}(+)$ : positive lymph node metastasis through surgery, N(-): no evidence of lymph node metastasis, PCR: real-time reverse transcriptasepolymerase chain reaction, EIPL: extensive intraoperative peritoneal lavage, IPC: intraperitoneal chemotherapy

\section{Conclusion}

EIPL therapy was developed as a prophylactic strategy for peritoneal recurrence, with the goal of improving the prognosis for patients with gastric cancer. In the present article, the risk factors on peritoneal recurrence from clinicopathological features of gastric carcinoma and the therapy's contribution to a remarkable improvement in the 5-year survival for gastric cancer patients with positive lavage cytology on prospective randomized controlled clinical trials was reviewed. From the viewpoint of prophylactic strategy against peritoneal recurrence, we propose the optimal and practical treatment protocol for gastric cancer.

\section{References}

Abe, S., Yoshimura, H., Tabara, H., Tachibana, M., Monden, N., Nakamura, T., \& Nagaoka, S. (1995). Curative resection of gastric cancer: limitation of peritoneal lavage 
cytology in predicting the outcome. Journal of Surgical Oncology, Vol.59, No.4, pp. 226-9

Balfour, D.C. (1973). Factors of significance in the prognosis of cancer of the stomach. Annals of Surgery, Vol.105, pp. 733-40

Bozzetti, F., Bonfanti, G., Morabito, A., Bufalino, R., Menotti, V., Andreola, S., Doci, R., \& Gennari, L. (1986). A multifactorial approach for the prognosis of patients with carcinoma of the stomach after curative resection. Surgery, Gynecology E Obstetrics , Vol.162, No.3, pp. 229-34

Boku, T., Nakane, Y., Minoura, T., Takada, H., Yamamura, M., Hioki, K., \& Yamamoto, M. (1990). Prognostic significance of serosal invasion and free intraperitoneal cancer cells in gastric cancer. The British Journal of Surgery, Vol.77, No.4, pp. 436-9

Bonenkamp, J.J., Songun, I., Hermans, J., Sasako, M., Welvaart, K., Plukker, J.T., van Elk, P., Obertop, H., Gouma, D.J., \& Taat, C.W. (1995). Randomised comparison of morbidity after D1 and D2 dissection for gastric cancer in 996 Dutch patients. Lancet, Vol.345, No. 8952, pp. 745-8

Benevolo, M., Mottolese, M., Cosimelli, M., Tedesco, M., Giannarelli, D., Vasselli, S., Carlini, M., Garofalo, A., \& Natali, P.G. (1998). Diagnostic and prognostic value of peritoneal immunocytology in gastric cancer. Journal of clinical oncology, Vol.16, No.10, pp. 3406-11

Burke, E.C., Karpeh, M.S. Jr., Conlon, K.C., \& Brennan, M.F. (1998). Peritoneal lavage cytology in gastric cancer: an independent predictor of outcome. Annals of Surgical Oncology, Vol.5, No.5, pp. 411-5

Bando, E., Yonemura, Y., Takeshita, Y., Taniguchi, K., Yasui, T., Yoshimitsu, Y., Fushida, S., Fujimura, T., Nishimura, G., \& Miwa, K. (1999). Intraoperative lavage for cytological examination in 1297 patients with gastric carcinoma. American Journal of Surgery, Vol.178, No.3, pp. 256-62

Broll, R., Weschta, M., Windhoevel, U., Berndt, S., Schwandner, O., Roblick, U., Schiedeck, T.H., Schimmelpenning, H., Bruch, H.P., \& Duchrow, M. (2001). Prognostic significance of free gastrointestinal tumor cells in peritoneal lavage detected by immunocytochemistry and polymerase chain reaction. Langenbeck's Archives of Surgery, Vol.386, No.4, pp. 285-92

Cunliffe, W.J., \& Sugarbaker, P.H. (1989). Gastrointestinal malignancy: rationale for adjuvant therapy using early postoperative intraperitoneal chemotherapy. British Journal of Surgery, Vol.76, No.10, pp. 1082-90

Cheong, J.H., Shen, J.Y., Song, C.S., Hyung, W.J., Shen, J.G., Choi, S.H., \& Noh, S.H. (2007). Early postoperative intraperitoneal chemotherapy following cytoreductive surgery in patients with very advanced gastric cancer. Annals of Surgical Oncology, Vol.14, No.1, pp. 61-8

Dicken, B.J., Graham, K., Hamilton, S.M., Andrews, S., Lai, R., Listgarten, J., Jhangri, G.S., Saunders, L.D., Damaraju, S., \& Cass, C. (2006). Lymphovascular invasion is associated with poor survival in gastric cancer: an application of gene-expression and tissue array techniques. Annals of Surgery, Vol.243, No.1, pp. 64-73

Fink, A., \& Longmire, W. (1991). Carcinoma of stomach. In: Textbook of Surgery, Subiston, D.C., (Ed.), 814-27, W.B. Saunders, Philadelphia, USA

Fujimoto, S., Takahashi, M., Mutou, T., Kobayashi, K., \& Toyosawa, T. (1999). Successful intraperiotneal hyperthermic chemoperfusion for the prevention of postoperative 
peritoneal recurrence in patients with advanced gastric carcinoma. Cancer, Vol.85, No.3, pp. 529-34

Fujimoto, T., Zhang, B., Minami, S., Wang, X., Takahashi, Y., \& Mai, M. (2002). Evaluation of intraoperative intraperitoneal cytology for advanced gastric carcinoma. Oncology, Vol.62, No.3, pp. 201-8

Hagiwara, A., Takahashi, T., Kojima, O., Sawai, K., Yamaguchi, T., Yamane, T., Taniguchi, H., Kitamura, K., Noguchi, A., \& Seiki, K. (1992). Prophylaxis with carbon-absorbed mitomycin against peritoneal recurrence of gastric cancer. Lancet, Vol.339, No. 8794, pp. 629-31

Hamazoe, R., Maeta, M., \& Kaibara, N. (1994). Intraperitoneal thermochemotherapy for prevention of peritoneal recurrence of gastric cancer. Final results of a randomized controlled study. Cancer, Vol.73, No.8, pp. 2048-52

Harrison, L.E., Karpeh, M.S., \& Brennan, M.F. (1998). Extended lymphadenectomy is associated with a survival benefit for node-negative gastric cancer. Journal of Gastrointestinal Surgery, Vol.2, No.2, pp. 126-31

Hayes, N., Wayman, J., Wadehra, V., Scott, D.J., Raimes, S.A., \& Griffin, S.M. (1999). Peritoneal cytology in the surgical evaluation of gastric carcinoma. British Journal of cancer, Vol.79, No. 3-4, pp. 520-4

Hioki, M., Gotohda, N., Konishi, M., Nakagohri, T., Takahashi, S., \& Kinoshita, T. (2010). Predictive factors improving survival after gastrectomy in gastric cancer patients with peritoneal carcinomatosis. World Journal of Surgery, Vol.34, No.3, pp. 555-62

Iitsuka, Y., Kaneshima, S., Tanida, O., Takeuchi, T., \& Koga, S. (1979). Intraperitoneal free cancer cells and their viability in gastric cancer. Cancer, Vol.44, No.4, pp. 1476-80

Ikeguchi, M., Oka, A., Tsujitani, S., Maeta, M., \& Kaibara, N. (1994). Relationship between area of serosal invasion and intraperitoneal free cancer cells in patients with gastric cancer. Anticancer Research, Vol.14, No. 5B, pp. 2131-4

Ikeguchi, M., Matsumoto, S., Yoshioka, S., Murakami, D., Kanaji, S., Ohro, S., Yamaguchi, K., Saito, H., Tatebe, S., Kondo, A., Tsujitani, S., \& Kaibara, N. (2005). Laparoscopicassisted intraperiotneal chemotherapy for the patients with scirrhous gastric cancer. Chemotherapy, Vol.51, No.1, pp. 15-20

Ishizone, S., Maruta, F., Saito, H., Koide, N., Sugiyama, A., Nakayama, J., \& Miyagawa, S. (2006). Efficacy of S-1 for patients with peritoneal metastasis of gastric cancer. Chemotherapy, Vol.52, No. 6, pp. 301-7

Japanese Research Society for Gastric Cancer. (1999). Japanese Classification of Gastric Carcinoma, First English Edition, Kanehara, Tokyo, Japan

Koga, S., Kaibara, N., Iitsuka, Y., Kudo, H., Kimura, A., \& Hiraoka, H. (1984). Prognostic significance of intraperitoneal free cancer cells in gastric cancer patients. Journal of Cancer Research and Clinical Oncology, Vol.108, No.2, pp. 236-8

Kaibara, N., Iitsuka, Y., Kimura, A., Kobayashi, Y., Hirooka, Y., Nishidoi, H., \& Koga, S. (1987). Relationship between area of serosal invasion and prognosis in patients with gastric carcinoma. Cancer, Vol.60, No.1, pp. 136-9

Kida, M., Tanabe, S., Watanabe, M., Kokutou, M., Kondou, I., Yamada, Y., Sakaguchi, T., \& Saigenji, K. (1998). Staging of gastric cancer with endoscopic ultrasonography and endoscopic mucosal resection. Endoscopy, Vol.30, No.1, pp. 64-8

Kodera, Y., Yamamura, Y., Shimizu, Y., Torii, A., Hirai, T., Yasui, K., Morimoto, T., \& Kato, T. (1999). Peritoneal washing cytology: prognostic value of positive findings in 
patients with gastric carcinoma undergoing a potentially curative resection. Journal of Surgical Oncology, Vol.72, No.2, pp. 60-5

Kodera, Y., Nakanishi, H., Ito, S., Yamamura, Y., Kanemitsu, Y., Shimizu, Y., Hirai, T., Yasui, K., Kato, T., \& Tatematsu, M. (2002). Quantitative detection of disseminated free cancer cells in peritoneal washes with real-time reverse transcriptase-polymerase chain reaction. Annals of Surgery, Vol.235, No.4, pp. 499-506

Kunisaki, C., Shimada, H., Nomura, M., Akiyama, H., Takahashi, M., \& Matsuda, G. (2002). Lack of efficacy of prophylactic peritoneal perfusion on subsequent peritoneal recurrence and survival in patients with advanced gastric cancer. Surgery, Vol.131, No.5, pp. 521-8

Kuramoto, M., Shimada, S., Ikeshima, S., Matsuo, A., Yagi, Y., Matsuda, M., Yonemura, Y., \& Baba, H. (2009). Extensive intraoperative peritoneal lavage as a standard prophylactic strategy for peritoneal recurrence in patients with gastric carcinoma. Annals of Surgery, Vol.250, No.2, pp. 242-6

Lim, S., Muhs, B.E., Marcus, S.G., Newman, E., Berman, R.S., \& Hiotis, S.P. (2007). Results following resection for stage IV gastric cancer; are better outcomes observed in selected patients subgroups? Journal of Surgical Oncology, Vol.95, No.2, pp. 118-22

Maruyama, K. (1987). The most important prognostic factors for gastric cancer patients. A study using univariate and multivariate analyses. Scandinavian Journal of Gastroenterology, Vol.22, pp. 63-8

Moriguchi, S., Maehara, Y., Korenaga, D., Sugiuchi, K., \& Nose, Y. (1992). Risk factors which predict pattern of recurrence after curative surgery for patients with advanced gastric cancer. Surgical Oncology, Vol.1, No.5, pp. 341-6

Marutsuka, T., Shimada, S., Shiomori, K., Hayashi, N., Yagi, Y., Yamane, T., \& Ogawa, M. (2003). Mechanisms of peritoneal metastasis after operation for non-serosa-invasive gastric carcinoma: an ultrarapid detection system for intraperitoneal free cancer cells and a prophylactic strategy for peritoneal metastasis. Clinical Cancer Research, Vol.9, No.2, pp. 678-85

Makino, T., Fujiwara, Y., Takiguchi, S., Miyata, H., Yamasaki, M., Nakajima, K., Nishida, T., Mori, M., \& Doki, Y. (2010). The utility of pre-operative peritoneal lavage examination in serosa-invading gastric cancer patients. Surgery, Vol.148, No.1, pp. 96-102

Nakamura, K., Ueyama, T., Yao, T., Xuan, Z.X., Ambe, K., Adachi, Y., Yakeishi, Y., Matsukuma, A., \& Enjoji, M. (1992). Pathology and prognosis of gastric carcinoma. Findings in 10,000 patients who underwent primary gastrectomy. Cancer, Vol.70, No.5, pp. $1030-7$

Ohgaki, M., Takahashi, T., Hagiwara, A., Yamasaki, J., \& Togawa, T. (1999). Effect of Extensive lymphnode dissection on the survival of early gastric cancer. HepatoGastroenterol, Vol.46, No.27, pp. 2096-9

Papanicolaou, G.N. (1963). Atlas of Exfoliative Cytology, Harvard University Press, Cambridge, USA

Ribeiro, U. Jr., Gama-Rodrigues, J.J., Safatle-Ribeiro, A.V., Bitelman, B., Ibrahim, R.E., Ferreira, M.B., Laudanna, A.A., \& Pinotti, H.W. (1998). Prognostic significance of intraperitoneal free cancer cells obtained by laparoscopic peritoneal lavage in patients with gastric cancer. Journal of Gastrointestinal Surgery, Vol.2, No.3, pp. 244-9 
Rosen, H.R., Jatzko, G., Repse, S., Potrc, S., Neudorfer, H., Sandbichler, P., Zacherl, J., Rabl, H., Holzberger, P., Lisborg, P., \& Czeijka, M. (1998). Adjuvant intraperitoneal chemotherapy with carbon-adsorbed mitomycin in patients with gastric cancer: results of a randomized multicenter trial of the Austrian Working Group for Surgical Oncology. Journal of Clinical Oncology, Vol.16, No.8, pp. 2733-8

Ribeiro, U. Jr., Safatle-Ribeiro, A.V., Zilberstein, B., Mucerino, D., Yagi, O.K., Bresciani, C.C., Jacob, C.E., Iryia, K., \& Gama-Rodrigues, J. (2006). Does the intraoperative peritoneal lavage cytology add prognostic information in patients with potentially curative gastric resection? Journal of Gastrointestinal Surgery, Vol.10, No.2, pp. 170-7

Rosenberg, R., Nekarda, H., Bauer, P., Schenck, U., Hoefler, H., \& Siewert, J.R. (2006). Free peritoneal tumor cells are an independent prognostic factor in curatively resected stage 1B gastric carcinoma. The British Journal of Surgery, Vol.93, No.3, pp. 325-31

Sauter, T., Hofbauer, F., \& Depisch, D. (1994). Adjuvant intraperitoneal cisplatin chemotherapy does not improve long-term survival after surgery for advanced gastric cancer. Journal of Clinical Oncology, Vol.12, No.5, pp. 970-4

Sugimachi, K., Maehara, Y., Horikoshi, N., Shimada, Y., Sakata, Y., Mitachi, Y., \& Taguchi, T. (1999). An early phase II study of oral S-1, a newly developed 5-fluorouracil derivative for advanced and recurrent gastrointestinal cancers. The S-1 Gastrointestinal Cancer Study Group. Oncology, Vol.57, No.3, pp. 202-10

Shirasaka, T., Yamamitsu, S., Tsuji, A., \& Taguchi, T. (2000). Conceptual changes in cancer chemotherapy: from an oral fluoropyrimidine prodrug, UFT, to a novel oral fluoropyrimidine prodrug, S-1, and low-dose FP therapy in Japan. Investigational New Drugs, Vol.18, No.4, pp. 315-29

Shimada, S., Yagi, Y., Shiomori, K., Honmyo, U., Hayashi, N., Matsuo, A., Marutsuka, T., \& Ogawa, M. (2001a). Characterization and proposal of the optimal therapeutic strategy for early gastric cancer. Surgery, Vol.129, No.6, pp. 714-9

Shimada, S., Yagi, Y., Honmyo, U., Shiomori, K., Yoshida, N., \& Ogawa, M. (2001b). Involvement of more than three lymph nodes predicts poor prognosis of early gastric carcinoma. Gastric Cancer, Vol.4, No.2, pp. 54-9

Shimada, S., Tanaka, E., Marutsuka, T., Honmyo, U., Tokunaga, H., Yagi, Y., Aoki, N., \& Ogawa, M. (2002). Extensive intraoperative peritoneal lavage and chemotherapy for gastric cancer patients with peritoneal free cancer cells. Gastric Cancer, Vol.5, No.3, pp. 168-72

Shimada, S., Yagi, Y., Shiomori, K., Shiomori, K., Marutsuka, T., Hirota, M., Honmyo, U., \& Ogawa, M. (2003). Proposal of the optimal and practical therapeutic strategy for gastric cancer. In Biological Response to Planned and Unplanned injuries: Cellular, molecular and genetic aspects, Ogawa, M., (Ed.), 389-7, International Congress Series, Elsevier, Amsterdam, Netherlands

Sano, T., Sasako, M., Yamamoto, S., Nashimoto, A., Kurita, A., Hiratsuka, M., Tsujinaka, T., Kinoshita, T., Arai, K., Yamamura, Y., \& Okajima, K. (2004). Gastric cancer surgery: morbidity and mortality results from a prospective randomized controlled trial comparing D2 and extended para-aortic lymphadenectomy--Japan Clinical Oncology Group study 9501. Journal of Clinical Oncology, Vol.22, No.14, pp. 276773

Saito, H., Osaki, T., Murakami, D., Sakamoto, T., Kanaji, S., Ohro, S., Tatebe, S., Tsujitani, S., \& Ikeguchi, M. (2007). Prediction of sites of recurrence in gastric carcinoma using 
immunohistochemical parameters. Journal of Surgical Oncology, Vol.95, No.2, pp. 123-8

Vogel, P., Rüschoff, J., Kümmel, S., Zirngibl, H., Hofstädter, F., Hohenberger, W., \& Jauch, K.W. (1999). Immunocytology improves prognostic impact of peritoneal tumour cell detection compared to conventional cytology in gastric cancer. European Journal of Surgical Oncology, Vol.25, No.5, pp. 515-9

Vogel, I., \& Kalthoff, H. (2001). Disseminated tumor cells. Their detection and significance for prognosis of gastrointestinal and pancreatic carcinomas. Virchows Archiv, Vol.439, No.2, pp. 109-17

Wu, C.C., Chen, J.T., Chang, M.C., Ho, W.L., Chen, C.Y., Yeh, D.C., Liu, T.J., \& P'eng, F.K. (1997). Optimal surgical strategy for potentially curable serosa-involved gastric carcinoma with intraperitoneal free cancer cells. Journal of the American College of Surgeons, Vol.184, No.6, pp. 611-7

Wu, C.W., Chiou, J.M., Ko, F.S., Lo, S.S., Chen, J.H., Lui, W.Y., \& Whang-Peng, J. (2008). Quality of life after curative gastrectomy for gastric cancer in a randomised controlled trial. British Journal of Cancer, Vol.98, No.1, pp. 54-9

Yonemura, Y., Ninomiya, I., Kaji, M., Sugiyama, K., Fujimura, K., Sawa, T., Katayama, K., Tanaka, S., Hirono, Y., \& Miwa, K. (1995). Prophylaxis with intraoperative chemohyperthermia against peritoneal recurrence of serosal invasion-positive gastric cancer. World Journal of Surgery, Vol.19, No.3, pp. 1-6

Yawata, A., Adachi, M., Okuda, H., Naishiro, Y., Takamura, T., Hareyama, M., Takayama, S., Reed, J.C., \& Imai, K. (1998). Prolonged cell survival enhances peritoneal dissemination of gastric cancer cells. Oncogene, Vol.16, No.20, pp. 2681-6

Yu, W., Whang, I., Suh, I., Averbach, A., Chang, D., \& Sugarbaker, P.H. (1998). Prospective randomized trial of early postoperative intraperitoneal chemotherapy as an adjuvant to resectable gastric cancer. Annals of Surgery, Vol.228, No.3, pp. 347-54

Yoo, C.H., Noh, S.H., Shin, D.W., Choi, S.H., \& Min, J.S. (2000). Recurrence following curative resection for gastric carcinoma. The British Journal of Surgery, Vol.87, No.2, pp. 236-42

Yamamoto, K., Shimada, S., Hirota, M., Yagi, Y., Matsuda, M., \& Baba, H. (2005). EIPL(extensive intraoperative peritoneal lavage) therapy significantly reduces peritoneal recurrence after pancreatectomy in patients with pancreatic cancer. International Journal of Oncology, Vol.27, No.5, pp. 1321-8

Yamamoto, M., Matsuyama, A., Kameyama, T., Okamoto, M., Okazaki, J., Utsunomiya, T., Tsutsui, S., Fujiwara, M., \& Ishida, T. (2009). Prognostic re-evaluation of peritoneal lavage cytology in Japanese patients with gastric carcinoma. Hepato-gastroenterology, Vol.56, No.89, pp. 261-5

Zhang, H., Liu, C., Wu, D., Meng, Y., Song, R., Lu, P., \& Wang, S. (2010). Does D3 surgery offer a better survival outcome compared to D1 surgery for gastric cancer? A result based on a hospital population of two decades as taking D2 surgery for reference. BMC Cancer, Vol.10, pp. No.6, 308 


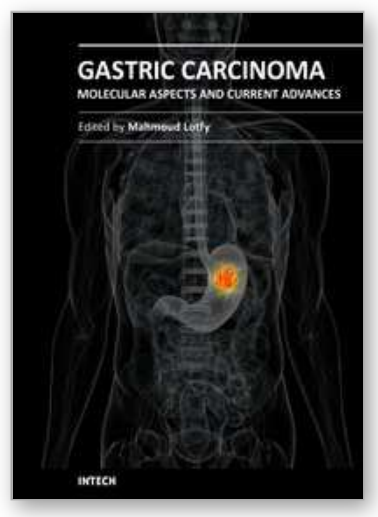

\section{Gastric Carcinoma - Molecular Aspects and Current Advances}

Edited by Prof. Mahmoud Lotfy

ISBN 978-953-307-412-2

Hard cover, 354 pages

Publisher InTech

Published online 15, June, 2011

Published in print edition June, 2011

Gastric cancer is one of the most common tumors worldwide. It has a heterogeneous milieu, where the genetic background, tumor immunology, oxidative stress, and microbial infections are key players in the multiple stages of tumorigenesis. These diverse factors are linked to the prognosis of the gastric cancer and the survival of gastric cancer patients. This book is appropriate for scientists and students in the field of oncology, gastroenterology, molecular biology, immunology, cell biology, biology, biochemistry, and pathology. This authoritative text carefully explains the fundamentals, providing a general overview of the principles followed by more detailed explanations of these recent topics efficiently. The topics presented herein contain the most recent knowledge in gastric cancer concerning the oncogenic signaling, genetic instability, the epigenetic aspect, molecular features and their clinical implications, miRNAs, integrin and E-cadherin, carbohydrateassociated-transferases, free radicals, immune cell responses, mucins, Helicobacter-pylori, neoadjuvant and adjuvant therapy, prophylactic strategy for peritoneal recurrence, and hepatic metastasis.

\section{How to reference}

In order to correctly reference this scholarly work, feel free to copy and paste the following:

Shinya Shimada, Masafumi Kuramoto, Akinobu Matsuo, Satoshi Ikeshima, Hiroshi Kuhara, Yoshiaki Ikuta and Hideo Baba (2011). Establishment of the Standard Prophylactic Strategy for Peritoneal Recurrence and Proposal of the Optimal Therapeutic Protocol for Gastric Cancer, Gastric Carcinoma - Molecular Aspects and Current Advances, Prof. Mahmoud Lotfy (Ed.), ISBN: 978-953-307-412-2, InTech, Available from:

http://www.intechopen.com/books/gastric-carcinoma-molecular-aspects-and-current-advances/establishmentof-the-standard-prophylactic-strategy-for-peritoneal-recurrence-and-proposal-of-the-op

\section{INTECH}

open science | open minds

\section{InTech Europe}

University Campus STeP Ri

Slavka Krautzeka 83/A

51000 Rijeka, Croatia

Phone: +385 (51) 770447

Fax: +385 (51) 686166

www.intechopen.com

\section{InTech China}

Unit 405, Office Block, Hotel Equatorial Shanghai

No.65, Yan An Road (West), Shanghai, 200040, China 中国上海市延安西路65号上海国际贵都大饭店办公楼 405 单元

Phone: +86-21-62489820

Fax: $+86-21-62489821$ 
(C) 2011 The Author(s). Licensee IntechOpen. This chapter is distributed under the terms of the Creative Commons Attribution-NonCommercialShareAlike-3.0 License, which permits use, distribution and reproduction for non-commercial purposes, provided the original is properly cited and derivative works building on this content are distributed under the same license. 